\title{
Monetary Policy Evaluation With Noisy Information
}

\author{
Athanasios Orphanides* \\ Board of Governors of the Federal Reserve System
}

October 1998

\begin{abstract}
This paper investigates the implications of noisy information regarding the measurement of economic activity for the evaluation of monetary policy. A common implicit assumption in such evaluations is that policymakers observe the current state of the economy promptly and accurately and can therefore adjust policy based on this information. However, in reality, decisions are made in real time when there is considerable uncertainty about the true state of affairs in the economy. Policy must be made with partial information. Using a simple model of the U.S. economy, I show that failing to account for the actual level of information noise in the historical data provides a seriously distorted picture of feasible macroeconomic outcomes and produces inefficient policy rules. Naive adoption of policies identified as efficient when such information noise is ignored results in macroeconomic performance worse than actual experience. When the noise content of the data is properly taken into account, policy reactions are cautious and less sensitive to the apparent imbalances in the unfiltered data. The resulting policy prescriptions reflect the recognition that excessively activist policy can increase rather than decrease economic instability.

Keywords: Policy evaluation, interest rate rules, data revisions, real-time data, optimal control, observation noise, inflation targeting.

JEL Classification System: E52, E58.

Correspondence: Division of Monetary Affairs, Board of Governors of the Federal Reserve System, Washington, D.C. 20551, USA. Tel.: (202) 452-2654, e-mail: aorphanides@frb.gov.

* I would like to thank Charles Calomiris, Bill English, Greg Hess, David Lindsey, Brian Madigan, Dick Porter, Simon van Norden and Kendrew Witt for valuable discussions and comments. The opinions expressed are those of the author and do not necessarily reflect views of the Board of Governors of the Federal Reserve System.
\end{abstract}




\section{Introduction}

Monetary policy decisions are made in real time and are based, by necessity, on preliminary data and estimates that contain considerable noise and are often substantially revised months or years after the event. While part of everyday life for policymakers, this aspect of the monetary policy process is often neglected in theoretical formulations of monetary policy, introducing a wedge between the promise of macroeconomic theory and the reality of macroeconomic practice.

Recognition of the complications resulting from the presence of noise is important for the study of monetary policy for two reasons: First, the evaluation of past policy is incorrect when it is based on the wrong data. That is, our understanding of the past becomes distorted. Second, the evaluation of alternative policy strategies is unrealistic and likely to mislead if it is based on the assumption that policy can react to either data that are not really available to policymakers when policy must be set or that are only available with substantial noise. That is, recommendations for better policy in the future become flawed.

Failing to recognize the extent of our ignorance leads to the false promise that an activist stabilization policy can have considerable success in fine-tuning the economy. Policy reactions that are unduly influenced by apparent imbalances in the data that may be mere artifacts of faulty measurement, however, risk increasing rather than reducing economic instability. This problem is by no means new to macroeconomic policy. For at least the past fifty years, it has been articulated many times by Milton Friedman, for instance in several of the essays in his 1953 and 1969 collections. As early as 1947, Friedman questioned the value of control theory for taming business cycle fluctuations by observing:

"Contemporary interpreters of the course of business have notoriously failed not only to predict the course of business but even to identify the current state of affairs. It is not abnormal for some to assert that we are in the early stages of deflation and others that we are entering into an inflation" (p. 314).

Rather surprisingly, half a century later and despite considerable advances in the evaluation of monetary policy performance, the quantitative relevance of this issue for monetary 
policy design has yet to receive proper attention. On one hand, those who believe that our knowledge of the economy is seriously lacking suggest adopting passive rules that forego short-run stabilization. On the other, proponents of activist policy implicitly suggest that the information problem does not present a serious handicap. Although the significance of the issue is frequently mentioned and some suggestive evidence that bears on it has been presented, by and large, concrete examination of the quantitative implications of the data imperfections for monetary policy design has been scant. ${ }^{1}$

This paper attempts to bridge this gap. My analysis draws on recent work that evaluates the performance of monetary policy formulated in terms of reactive interest-rate-based policy rules. Using a simple estimated model of the U.S. economy, I follow recent studies and evaluate alternative policy rules to assess the proper degree of monetary policy responsiveness to fluctuations in inflation and economic activity. However, instead of only performing these evaluations based on the assumption that the policymaker can observe the data promptly and accurately, I perform parallel experiments that recognize that in real time the policymaker observes the data with noise. Using the actual historical data that were available to policymakers in real time I am able to calibrate the degree of data imperfections to exactly match the level of noise faced by policymakers in practice. Comparison of the resulting alternative counterfactual experiments then presents a straightforward quantification of the impact of data noise on monetary policy.

The results confirm the common finding obtained in many recent stochastic simulation studies that, in the absence of noise, activist control could substantially improve upon

\footnotetext{
${ }^{1}$ Earlier work that bears on this is issue includes Meltzer (1987), who presents evidence confirming substantial errors in assessing the economic outlook to argue against activist policy and McCallum (1994) who recognizing the difficulty of policy formulated with contemporaneous information, suggests that activist policy should be based on lagged information. Orphanides (1997) demonstrates the magnitude and persistence of the data problem in the context of a fixed activist policy rule. Several authors, including Taylor (1998) and McCallum and Nelson (1998), indicate that measurement problems should be of concern for activist stabilization, and many others, including Estrella and Mishkin (1998), Orphanides and van Norden (in process), Kuttner (1992), and Wieland (1998) discuss the difficulties associated with the measurement of the concept of full employment in the context of stabilization policy. Cecchetti (1996) examines the related problems associated with the measurement of inflation. The recent surveys on monetary policy by McCallum (1997), and Clarida, Gertler and Gali (1998) also discuss this issue.
} 
the actual macroeconomic performance of the U.S. economy. However, I show that this improvement is illusory: It provides a seriously distorted picture of feasible outcomes that would occur once the noise in the data is taken into account. The resulting outcomes that would obtain had the supposedly optimal policies been adopted are in fact worse than the actual performance of the U.S. economy over the 1980s and early 1990s. The presence of noise acts as a counterweight to the highly responsive policy that would otherwise be appropriate to adopt. Recognition of the false promise of activist policies when the state of the economy cannot be confidently ascertained by the data leads to policy that tends to downplay the apparent short run fluctuations in the economy.

Even considering the limitations of the information available to policymakers in real time, however, my results suggest that there may be some room for short-run stabilization policy. In this sense, the suggested strategy for monetary policy is neither at the extreme of total passivity nor at the alternative of reckless activism. Fundamentally, these results provide quantitative support for Friedman's (1958) call for balanced policy:

"There is a saying that the best is often the enemy of the good, which seems highly relevant. The goal of an extremely high degree of economic stability is certainly a splendid one; our ability to attain it, however, is limited; we can surely avoid extreme fluctuations; we do not know enough to avoid minor fluctuations; the attempt to do more than we can will itself be a disturbance that may increase rather than reduce instability. But like all such injunctions, this one too must be taken in moderation. It is a plea for a sense of perspective and balance, not for irresponsibility in the face of major problems or for failure to correct past mistakes" (p. 187).

Paradoxically, by demonstrating that actual monetary policy since 1980 has not been activist enough to live up to the "promise" of stabilization policies that appear optimal when the information limitations are ignored, my analysis suggests that policy over this period may have actually exhibited the perspective and balance Friedman had called for. Indeed, recognition of the limitations facing policymakers in practice significantly enhances our understanding of forces that may have shaped policy over this period. My results provide an explanation both for the aversion of policy to commit to any specific reactive policy rule, 
as well as for the apparent caution characterizing monetary policy in practice. As Blinder (1998) noted explaining the policy process during his recent tenure as Vice-Chairman at the Federal Reserve, "a little stodginess at the central bank is entirely appropriate." I show that data noise induces such stodginess. Interestingly, as I discuss, this effect is distinct from the cautious behavior sometimes associated with model parameter uncertainty, as in Brainard (1967). Further, since the degree of uncertainty regarding the reliability of incoming information continuously changes with the evolution of the economic environment, the apparent degree of caution in policy decisions changes in tandem. The result, as Chairman Greenspan (1997) pointed out in a recent discussion of monetary policy rules, is that "some element of discretion appears to be an unavoidable aspect of policymaking," and policy will appear eclectic, even though the Federal Reserve "has sought to exploit past patterns and regularities in a systematic way." In the end, "policymakers shy away from rule-based decisions because the rules assume that they know too much," as Kohn (1998) noted.

\section{The Nature of the Information Problem}

I restrict my attention to a family of simple reactive rules that has been the subject of a large and rapidly growing number of monetary policy evaluation studies over the past few years. These rules specify that the Federal Reserve set the federal funds rate (the short nominal interest rate) as a linear function of output deviations from potential - the output gap, $y$, and the difference between actual inflation, $\pi$, and its desired level, $\pi^{*}$. Defining the short-term real interest rate, $r$, as the nominal interest rate, $f$, minus inflation, the stance of monetary policy can be described by comparing the real rate to its long-run equilibrium level, $r^{*}$. A useful way to organize these policy rules, then, is:

$$
r-r^{*}=\gamma\left(\pi_{t}-\pi^{*}\right)+\delta y_{t}
$$

An appealing feature of this specification is that it encompasses the interest-rate rule suggested as descriptive of recent U.S. monetary policy by Taylor (1993). Taylor's rule can be 
obtained by re-writing equation (1) in terms of the federal funds rate:

$$
f_{t}=r^{*}+\pi_{t}+\gamma\left(\pi_{t}-\pi^{*}\right)+\delta y_{t},
$$

and substituting the parameters $r^{*}=\pi^{*}=2$, and $\gamma=\delta=1 / 2$. Starting with the largescale model comparison studies reported in Bryant et al (1993), rules of this type have been investigated in depth in simulation studies with a variety of models spanning a wide spectrum of behavioral structure, modeling complexity and assumptions regarding the nature of expectations. (See, e.g. Henderson and McKibbin, 1993; Levin, 1996; Ball, 1997; Orphanides et al, 1997; and the collection of studies in Taylor, 1998b.) As Taylor (1998a) observes in surveying this work, the simulation analysis has already produced a number of positive conclusions. Taylor's rule appears to perform rather well in a variety of models and as such appears to be quite robust to model specification. However, these studies also suggest that Taylor's rule is not efficient in terms of stabilizing output and inflation, and specifically find that rules with considerably higher response coefficients than Taylor's suggested parameters, $\gamma=\delta=1 / 2$, would result in better performance.

The information problem associated with these policy rules is that the performance of the rules is examined under the maintained assumption that the policymaker has accurate information regarding the current values of inflation and the output gap at his disposal when setting the interest rate. In fact, however, both inflation and the output gap are measured with considerable noise. Thus, a more accurate representation of reality should take into account that the policymaker's observation regarding inflation, $\tilde{\pi}$, and the output gap, $\tilde{y}$, at the time policy decisions are being made, may in fact differ from the true underlying levels of inflation, $\pi$, and the output gap, $y$. Letting $x$ denote the noise in the observation of inflation and $z$ the noise in the observation of the output gap, we have:

$$
\begin{aligned}
& \pi_{t}=\tilde{\pi}_{t}+x_{t} \\
& y_{t}=\tilde{y}_{t}+z_{t}
\end{aligned}
$$


Further, the true real interest rate corresponding to a chosen nominal interest rate is not the observed difference between the nominal interest rate and observed inflation, $\tilde{r}$, but the unobserved difference between the nominal interest rate and actual inflation, $r .^{2}$

Once the presence of noise is recognized, it is evident that the proper specification of a simple rule specified to set the interest rate in terms of observed inflation and output is not equation (1) but rather:

$$
\tilde{r}_{t}-r^{*}=\gamma\left(\tilde{\pi}_{t}-\pi^{*}\right)+\delta \tilde{y}_{t}
$$

where $\tilde{r} \equiv f-\tilde{\pi}$. Of course, in the absence of noise, $\pi_{t}=\tilde{\pi}_{t}$ and $y_{t}=\tilde{y}_{t}$ in which case equations (1) and (2) are identical. Written in terms of the true measures of inflation and the gap, the interest rate policy corresponding to rule (2) is:

$$
r_{t}-r^{*}=\gamma\left(\pi_{t}-\pi^{*}\right)+\delta y_{t}-\underbrace{\left((1+\gamma) x_{t}+\delta z_{t}\right)}_{\text {noise }}
$$

This reveals the nature of the information problem. By choosing positive response coefficients to the inflation and output gaps - as is appropriate for the stabilization of output and inflation - the policymaker inadvertently also reacts to the noise processes. This introduces undesirable movements in the interest rate, which feed back to the economy and generate unnecessary fluctuations in output and inflation.

Of course, a policymaker who recognizes that the information at his disposal is not entirely accurate need not naively follow a rule deemed efficient only when noise is erroneously ignored. Indeed, as is obvious from (3), by choosing to respond less aggressively to inflation and output, the policymaker can reduce the influence of the noise. A fundamental tension is embedded in a simple rule that responds to noisy information. On the one hand, active stabilization policy in the absence of noise suggests rather strong responses to inflation and output. On the other hand a muted response would offer the advantage of reducing inap-

\footnotetext{
${ }^{2}$ By concentrating attention on an ex-post concept of the real interest rate, instead of an ex-ante concept, I sidestep the issue of separating the noise in the policymaker's observation of inflation from the noise in the policymaker's observation of the public's inflation expectations. I discuss the obvious omitted complications later on. As written, the policy rule also reflects the assumption that the policymaker knows the level of the equilibrium real interest rate, $r^{*}$. In practice, this introduces additional complications for monetary control.
} 
propriate activism. As a result of these conflicting forces, an efficient policy that properly accounts for the noise in the data might seek a balance and call for less activism than would be appropriate in the absence of noise.

\section{A Minimalist Model}

Most of the models employed in policy rule evaluations are sufficiently complicated that the reaction function in equation (1) is at best only approximately efficient. To assess the degree to which observation noise influences the performance of otherwise efficient policy rules, however, it is more convenient to start with a baseline case under which optimal policy can be exactly characterized by the simple reaction function in equation (1). To that end, I rely on the following minimalist model of the economy. The structure follows closely the model employed by Orphanides and Wilcox (1996) in their study of alternative approaches to disinflation. It is very similar to the model adopted by Ball (1997) and Svensson (1997) for the study of efficient policy rules for inflation targeting.

In every period the evolution of inflation and output depends on just four things: the levels of inflation and output in the previous period, monetary policy and random shocks. Inflation is determined by an accelerationist Phillips curve:

$$
\pi_{t}=\pi_{t-1}+\alpha y_{t}+e_{t}
$$

where $\alpha$ is positive. Output is determined by lagged output and interest rates according to:

$$
y_{t}=\rho y_{t-1}-\xi\left(r_{t-1}-r^{*}\right)+u_{t}
$$

where $\xi$ is positive, and $\rho$ is between zero and one. Thus, output tends to revert to its potential, following a first order autoregressive process when monetary policy is neutral, and also responds linearly to deviations of the short-term real interest rate from its equilibrium level, $r^{*}$.

The stochastic shocks in this economy are summarized by a disturbance to inflation, $e_{t}$, which can be seen as capturing "supply" shocks, and a disturbance to output, $u_{t}$, which 
captures "demand" shocks. For simplicity, I assume that these disturbances are drawn from independent normal distributions with zero means and variances $\sigma_{e}^{2}$ and $\sigma_{u}^{2}$. Monetary policy operates with a lag, and consequently the policymaker can never completely offset the effects of contemporaneous shocks on output and inflation. Since policy can be adjusted until the end of any given period, however, I follow the usual assumption that the policymaker utilizes all information at his disposal including information regarding the contemporaneous shocks for period $t$ before setting the interest rate. Thus, the policymaker can set the interest rate in response to his observation of contemporaneous inflation and output.

The major advantage of this simple model is that the underlying state of the economy at the end of a period is completely described by just two things, inflation and the output gap during the period. Of course, this is too simplistic to characterize the short-run dynamic behavior of the economy at a high frequency, such as at monthly or quarterly intervals. Rather, a coarser division of time is required. As a result, I interpret the length of the period to be half a year. Later on, I show that despite its simplicity, this model can capture the characteristics of semiannual U.S. data reasonably well. Another advantage is that this model does not require an explicit exposition of economic agents' expectations. This simplifies tremendously its properties in the presence of noise. I return to the complications presented by expectations for the analysis later on.

The objective of monetary policy is to minimize a weighted sum of the unconditional variances of inflation and the output gap.

$$
\mathcal{L}=\omega \operatorname{Var}\left(\pi_{t}-\pi^{*}\right)+(1-\omega) \operatorname{Var}\left(y_{t}\right)
$$

The weight, $\omega$, which is assumed to be a fixed fraction between zero and one, reflects the tenacity with which the policymaker is willing to pursue inflation stabilization in the short run, at the expense of continuously aiming for full employment. A weight approaching one would reflect King's (1997) "inflation nutter," a policymaker who places no weight on output stabilization and follows "strict" inflation targeting. Smaller weights would corre- 
spond, increasingly, to greater relative concern for output stabilization, suggesting "flexible" inflation targeting in Svensson's (1997) terminology.

\subsection{Perfect Information}

Under the assumption that the observations of inflation and the output gap are timely and not subject to noise, derivation of the optimal policy in this model is a straightforward exercise in linear-quadratic control. (See the Appendix for details.) The solution takes exactly the form of equation (1). That is, in the absence of noise, optimal policy is described by:

$$
r_{t}-r^{*}=\gamma^{N}\left(\pi_{t}-\pi^{*}\right)+\delta^{N} y_{t}
$$

The optimal response coefficients, $\gamma^{N}$ and $\delta^{N}$, can be computed analytically in terms of the model parameters, $\alpha, \xi$ and $\rho$, and the policymaker's preferences summarized by the weight, $\omega$.

$$
\gamma^{N}=\frac{-\alpha \omega+\sqrt{4(1-\omega) \omega+(\alpha \omega)^{2}}}{2(1-\omega) \xi}
$$

and

$$
\delta^{N}=\frac{\rho}{\xi}
$$

As can be seen, the optimal response to the output gap, $\delta^{N}$, is simply a function of the persistence of output, $\rho$, and the interest responsiveness of aggregate demand, $\xi$. Specifically it does not depend on the relative weight the policymaker places on inflation stabilization. Although convenient, this is a quite special result that depends on the timing structure of the model. The optimal response to inflation, $\gamma^{N}$, depends on all parameters of the model, including $\omega$. In fact, $\gamma^{N}$ is increasing in the inflation stabilization weight, with a lower limit of zero as $\omega \rightarrow 0$ and an upper limit of $1 / \alpha \xi$ as $\omega \rightarrow 1$. This latter response generates an output gap exactly equal to what is necessary to bring inflation to its target in just one period (in expectation), as an "inflation nutter" would be expected to attempt to do. 


\subsection{Naive Policy}

The policy reaction function derived under the assumption of perfect state information also serves as a useful baseline case to consider when noise actually is present in the data. To be sure, the resulting policy:

$$
\tilde{r}_{t}-r^{*}=\gamma^{N}\left(\tilde{\pi}_{t}-\pi^{*}\right)+\delta^{N} \tilde{y}_{t}
$$

is not necessarily efficient since it does not reflect the proper informational assumptions. It is, however, exactly the policy that would be adopted if one were tempted to take the results of the perfect information analysis at face value and blindly apply the suggested recommendations using the data available. In this sense, this rule reflects naive policy.

\subsection{Efficient Simple Rules}

Naive monetary control is efficient in the absence of noise but is clearly inefficient when noise is present in the data. To characterize the set of comparable efficient policies when the policymaker correctly takes the presence of noise into consideration for policy design requires solution of a constrained minimization problem. The solution is the set of response coefficients $\gamma^{S}$ and $\delta^{S}$ which minimize the policymaker's objective for different possible values of the preference weight $\omega$, when policy follows the simple rule:

$$
\tilde{r}_{t}-r^{*}=\gamma^{S}\left(\tilde{\pi}_{t}-\pi^{*}\right)+\delta^{S} \tilde{y}_{t}
$$

and the policymaker properly accounts for the noise in the data.

Obviously, in the absence of noise, the efficient policy will coincide with the naive policy reaction function. When noise is present in the data, determination of the efficient rules requires a complete characterization of the stochastic processes governing the observation noise. Anticipating the empirical description of the data in section 4, I assume that the inflation noise, $x$, can be adequately modeled as a serially uncorrelated process and that the output gap noise, $z$, is described by the autoregressive process:

$$
z_{t}=\beta z_{t-1}+v_{t}
$$


I assume that $x$ and $v$ are drawn from zero mean normal distributions with variances $\sigma_{x}^{2}$ and $\sigma_{v}^{2}$, respectively. With these additional assumptions, we can describe the economy for an arbitrary choice of response parameters in the simple rule (7) in terms of a first order autoregressive system of the vector $\left(\pi_{t}-\pi^{*}, y_{t}, z_{t}, r_{t}-r^{*}\right)^{\prime}$. The asymptotic covariance of this vector can be computed analytically from the resulting autoregressive system in terms of the parameters of the system, $\alpha, \rho, \xi$ and $\beta$, the preference weight, $\omega$, the rule responses $\gamma$ and $\delta$ and the covariance of $e_{t}, u_{t}, x_{t}$ and $v_{t}$. Using this covariance matrix, I resort to numerical optimization to determine the efficient rule responses $\gamma^{S}$ and $\delta^{S}$ that minimize the associated policymaker loss function.

\subsection{Optimal Control and Certainty Equivalence}

Although the focus of my analysis is efficient simple rules, it is instructive to also examine the performance of the economy with optimal control that properly accounts for the noisy data. When the underlying data describing the economy are noisy, the most recent observations do not provide the best assessment of the underlying inflation and output gap measures by themselves. Recognizing that he receives noisy data, the policymaker must first attempt to remove the noise component from the data as best as possible, before formulating his policy. This filtering of the data entails forming the conditional expectation of the true underlying states, $\pi_{t}$ and $y_{t}$, consistent with the most recent data, $\tilde{\pi}_{t}$ and $\tilde{y}_{t}$, and the policymaker's model and prior assessment of the economy. The outcome of this filtering, $\hat{\pi}_{t}$, and $\hat{y}_{t}$, represents the policymaker's best assessment of the state of inflation and output in the economy. With substantial noise, this assessment could be tenuous and the policymaker may recognize that he cannot ascertain the state of the economy with much confidence. However, once this first step is completed, application of the certainty equivalence principle yields the optimal policy:

$$
\hat{r}_{t}-r^{*}=\gamma^{N}\left(\hat{\pi}_{t}-\pi^{*}\right)+\delta^{N} \hat{y}_{t}
$$


where $\hat{r}_{t} \equiv f_{t}-\hat{\pi}_{t}$. The policy described by equation (9), coupled with the appropriate filtering constitutes the optimal policy design in this economy. However, the rule cannot be written in terms of just the current values of the observed data, $\tilde{\pi}_{t}$ and $\tilde{y}_{t}$, and is not equivalent to the simple efficient rule (7). In essence, a simple efficient rule setting the interest rate in terms of observed noisy data collapses the filtering and control steps of the optimal stochastic control solution to the policymaker's problem into a single step. This allows policy to be formulated in terms of just current data but entails some loss of performance. $^{3}$

\section{Data and Model Parameters}

To assess the extent of noise in the data requires a comparison of the real-time data available to the policymakers when interest rate decisions are made as well as measures of the true underlying state of the economy. Information is needed for three concepts, nominal output, the output deflator and potential output. The only additional variable needed in the model, the federal funds rate, is not subject to similar measurement problems. For the information available to policymakers in real time, I rely on data associated with the production of the Federal Reserve Board staff's analysis for the macroeconomic outlook. This is presented in a document that is prepared for the FOMC before each FOMC meeting - the Greenbook. A detailed description of this data is provided in Orphanides (1997). As this information only becomes available to the public with a five-year lag, my data end in 1992. The beginning of my sample is 1980 as I was not able to recover earlier data for the output gap. From each year, I use data from the May Greenbook for the first semi-annual observation and the November Greenbook for the second semi-annual observation, reflecting the model assumption that the choice of the average federal funds rate for a period incorporates information

\footnotetext{
${ }^{3}$ This discussion can also help clarify a potential source of confusion relating to the application of certainty equivalence in this setting. Although noise appears to represent uncertainty that is "additive," the certainty equivalence principle does not imply that the optimal rule is impervious to it. The sense in which additive uncertainty does not matter in this setting is not with regard to the variance of the noise in the data but with regard to the variance of the conditional expectation which characterizes the policymaker's best assessment of the state of inflation and output after the noise is filtered from the data.
} 
available towards the end of the period.

Historical information on nominal output, the output deflator, and potential output, the three central series for my analysis, is continuously refined and updated. Given the difficulties associated with their measurement, including problems with the underlying disaggregated data and a continuing debate regarding methodological issues, it is impossible to know what the true value of either inflation or the output gap has been in the past with much confidence. ${ }^{4}$ If, however, measurement regarding the past improves as time progresses, using the most recent available data might offer a sufficient approximation of the "truth" to provide a useful measure of the noise in the real-time data. Here, I rely on data available at the end of 1994 as providing proxies of the true measures of inflation and the output gap for the sample. ${ }^{5}$

Figures 1 and 2 plot the real-time and final data for inflation and the output gap respectively. Table 1 presents summary statistics for these series and the inflation and output gap noise. As would be expected for noisy data, the standard deviations of the realtime series, $\tilde{y}$ and $\tilde{\pi}$, are larger than those of the final data, $y$ and $\pi$. The noise in the inflation data, $x$, defined as the difference between the final and real-time series, is considerable at times, ranging from -1.91 to +1.53 percentage points. However no significant bias or serial correlation patterns can be detected. (The mean is 0.12 and the first order serial correlation is -0.07.) Thus, modeling $x$ as a white noise process appears reasonable. The estimated standard deviation of the process, an estimate for $\sigma_{x}$, is 0.69 percent.

The data reveal a different pattern for the output gap noise. The difference between

\footnotetext{
${ }^{4} \mathrm{~A}$ voluminous literature has examined the problems associated with and suggested improvements for the measurement of both output and inflation. Zellner (1959), Cole (1969a), and Mankiw and Shapiro (1976) have studied the revisions in output measures. The annual revisions of the national income and product accounts published in the Survey of Current Business detail the continuing effort for improvement in the data. Orphanides and van Norden (in process) document the impact of these revisions on the measurement of the output gap in real time. The measurement of inflation has been the subject of heightened attention in recent years including the studies by Boskin et al (1996), Shapiro and Wilcox (1996), and Bryan et al (1997).

${ }^{5}$ The choice is driven by data availability. Although more recent vintages of output and the output deflator data are available from the Commerce Department, 1994 currently marks the latest corresponding series for historical potential output data available from the Federal Reserve.
} 
the final and real-time output gap, $z$, is noticeably different from zero on average, and exhibits substantial serial correlation. An AR(1) process, however, provides a satisfactory model. Estimation with least squares yields the following estimates (standard errors in parentheses):

$$
z_{t}=0.911 z_{t-1}+v_{t}, \quad \hat{\sigma}_{v}=0.93
$$

The 0.911 point estimate for the output gap noise persistence parameter, $\beta$, confirms the substantial serial correlation in the output gap noise. ${ }^{6}$ Although the output gap noise deviated noticeably from zero in this sample - the average between the final and real-time data is 2.34 percentage points - allowing for an intercept term in the regression yields an estimate not statistically different from zero. That is, the appearance of a bias in the realtime data relative to the final series in this particular sample is entirely consistent with the theoretical prior that the process is unbiased, given the high positive serial correlation and the small sample size. As a result, I impose the restriction that the noise is a mean zero process on the data to recover the estimates for $\beta$ and $\sigma_{v}$.

To obtain parameters for the output and inflation equations of the model, I estimate equations (4) and (5) with least squares using semiannual data for the sample from 1980 to 1992, the same period over which I am able to construct the data for the noise.

Inflation equation

$$
\pi_{t}=\pi_{t-1}+0.180 y_{t}+e_{t}, \quad \hat{\sigma}_{e}=1.04
$$

Output equation

$$
y_{t}=+\underset{(0.611)}{0.835}+\underset{(0.101)}{0.764} y_{t-1}-\underset{(0.135)}{0.293} r_{t-1}+u_{t}, \quad \hat{\sigma}_{u}=1.16
$$

Despite its simplicity, the model characterizes semiannual U.S. data over this period rather well. The data are compatible with the restrictions embedded in the Phillips curve. An unrestricted regression yields a near zero intercept and the unrestricted estimate of the

\footnotetext{
${ }^{6}$ In fact, the data would not reject the hypothesis that $z$ is integrated of order 1 . However, given that in such short samples (13 years), tests of the null hypothesis of a unit root often lack power, and given the strong theoretical prior that the noise should be stationary, this should not be a major concern.
} 
lagged inflation coefficient, 0.98 , is also insignificantly different from the imposed value of one. (Essentially similar results are also obtained with instrumental variables estimation, using lags of inflation, output and interest rates as instruments.) Compared to the standard deviations of inflation and the output gap over this period (2.27 and 2.44, respectively), the standard errors of the two regressions (1.04 and 1.16, respectively) are not very large. And the three key parameters of the model, the slope of the Phillips curve, $\alpha$, the persistence of output, $\rho$, and the interest rate responsiveness of output, $\xi$, are fairly tightly estimated.

To assess the realism of the estimated model it is also useful to compare its properties with other models employed for simulation experiments in policy rule evaluations. The models by Rudebusch and Svensson (1998) and Ball (1997) are particularly useful for this purpose since both have a structure that is similar to the model I employ, rendering the comparison straightforward. Ball's model shares a structure as simple as the one here in that lagged output and lagged inflation suffice to characterize the economy's state. However, Ball does not estimate his model and instead calibrates it to an annual frequency. Rudebusch and Svensson (1998) estimate their model with quarterly data, but as would be expected, require additional lags of inflation and output to characterize the economy's state. They also provide a useful comparison of their model with other larger models, in particular the Federal Reserve's MPS model reported by Mauskopf (1995).

The two key dimensions for assessing the realism of the model for monetary policy evaluation are the cost of disinflation and the sensitivity of output to the policy instrument. The implicit estimate of the sacrifice ratio is 2.9 , that is, the model requires almost three years of a one percentage point output gap to induce a one percentage point change in the inflation rate. This is somewhat larger than Ball's assumption of 2.5 but smaller than the 3.3 estimate in Rudebusch and Svensson (1998) which coincides with the estimate implicit in the MPS model. To compare the interest sensitivity of aggregate demand, I computed the dynamic response of output to a two year tightening of the federal funds rate by 100 basis points, following the experiments reported in Mauskopf (1995) and also in Rudebusch 
and Svensson (1998). The cumulative output loss at the end of two years in my model is -0.66 percent. This compares with -0.48 percent in the Rudebusch and Svensson model, -0.52 in the MPS model and -1.0 percent in the Ball model.

\section{Policy Evaluation}

Armed with a parameterized model of the U.S. economy, estimates of the variances of the underlying supply and demand shocks and, importantly, estimates of the stochastic processes of the noise in the inflation and output gap data, I next provide comparisons of the performance from naive policies, efficient simple rules, and optimal control in the presence of noise. My objective is limited to showing the implications of erroneously ignoring the presence of noise in the data. As a result, in all experiments, I maintain a litany of other assumptions embedded in policy rule evaluations of this nature, such as that the model is assumed to be properly specified, that the estimated parameters are constant over time, invariant to the choice of policy, and known with certainty by the policymakers, and that the stochastic processes of the shocks, including the noise processes, are constant over time and known with certainty. Since the spirit of my analysis is to illustrate the limitations of one specific aspect of policy evaluation, it is only proper to acknowledge the presence of other significant limitations at the outset.

\subsection{Naive Policy}

My benchmark for comparison is the performance of the economy if rules deemed optimal in the absence of noise were naively followed. The solid line in figure 3 shows the counterfactual inflation-variability frontier that would result if policy were set according to (6) and noise were absent from the data. The different points on the line trace the performance of the economy in terms of the unconditional variances of inflation and the output gap that correspond to this policy for different values of the inflation stabilization preference weight, $\omega$. The point marked with a dot shows the actual variances of inflation and the output gap over the same sample from which the stochastic shocks are drawn, that is 1980-1992. 
This should be interpreted with caution since the sample moments over this period may not be strictly comparable to the unconditional variances due to the substantial disinflation reflected in this sample. Despite this limitation, however, a rather obvious conclusion that appears to emerge from a direct comparison of the historical performance with the frontier is that policy over this period has been rather far away from the efficient variability frontier. This model, therefore, confirms the usual finding that, however commendable monetary policy may have been over this period, substantial room for improvement would appear to remain.

Of course, by ignoring the noise in the data, the frontier shown in the solid line presents outcomes that are infeasible in practice, even if all the other assumptions in the model held. Computation of the outcomes that would have resulted if the naive policies were followed ought to properly account for the noise in the data. Doing so results in the variability frontier shown in the dashed line in figure 3.

With the appropriate inclusion of the forgotten noise, it becomes evident that the policies recommended as optimal result in performance that is not only substantially worse than advertised, but is also worse than the actual historical outcome of the variability of output and inflation in the data.

\subsection{Efficient Simple Rules and Optimal Control}

Policymakers who properly take into account the noise in the data, of course, can improve upon the naive policy rules. Figure 4 compares the naive frontier in the presence of noise derived in figure 3 to the variability frontier corresponding to the family of efficient simple rules (equation (7), the dotted line), and the variability frontier corresponding to optimal control policies in this model (equation (9), the dash-dot line).

As is evident, policies that properly account for the noise in the data can yield substantial improvements over the naive policies. The optimal control frontier presents the best feasible set of outcomes under the assumptions of the model. However, given the questions regarding the robustness of optimal control policies to model misspecification (as recently presented 
in Levin et al, 1998, for instance), it is more instructive to concentrate on the frontier corresponding to the efficient simple rules (7). The historical performance of the U.S. economy over this period is right on the efficient simple rule frontier, leaving little room for the claim that much improvement in performance would have been possible with better macroeconomic control.

\subsection{The Efficiency of Policy Stodginess}

Examination of the simple efficient rules in the presence of noise relative to the naive control rules that are efficient in the absence of noise also permits comparison of the suggested responsiveness of the federal funds rate instrument to the observed inflation and output gap. To that end, it is useful to parameterize the response parameters, $\gamma$ and $\delta$, of the simple efficient rule (7) to indicate their variation with a scale parameter measuring the noise in the data, $s$, and the inflation stabilization preferences weight, $\omega$. The noise scale parameter, $s$, measures the presence of noise in units of standard deviations relative to the actual noise in the data. That is, $s=1$ corresponds to noise of the magnitude estimated in the data, $s=2$ reflects noise with twice the standard deviation of both the inflation and output gap noise in the data, and of course, $s=0$ collapses to the baseline case of no noise.

Figure 5 provides a graphical summary of these results. Points on the chart show the optimal response pairs $\gamma$ (horizontal axis) and $\delta$ (vertical axis) corresponding to different levels of noise, $s$, and preference weight, $\omega$. The three dotted lines correspond to the loci of efficient responses for three different levels of noise, $s=0, s=1$, and $s=2$. Each locus shows the efficient responses for different values of $\omega$, with points to the right corresponding to greater weights. The three solid lines in the figure correspond to loci of efficient responses for three different levels of the inflation stabilization weight, $\omega$. The three reference weights $\omega=0.25, \omega=0.5$ and $\omega=0.75$, reflect valuation of inflation stability relative to output stability in the ratios 1:3, 1:1 and 3:1, respectively. Each locus shows the efficient responses for different values of $s$. The points with the highest values for $\gamma$ and $\delta$ correspond to the baseline of no noise $s=0$, with the direction of the arrows indicating the direction in 
which the efficient choices for $\gamma$ and $\delta$ move as noise increases. As can be seen, regardless of the preference weight, the response to the output gap in particular drops sharply as the magnitude of noise increases. For convenience, table 2 shows the efficient response parameters for selected values of $s$ and $\omega$.

In summary, the presence of noise in the data acts as a counterweight to the highly responsive policy that policymakers might have otherwise adopted to stabilize the economy. This result can be understood intuitively. When a policymaker suspects that the information he is being provided with regarding the state of the economy is subject to significant noise, he should be reluctant to adjust his policy instrument as much as he would if he could trust the picture of the economy being painted with the data. This suggests that policy will be less activist than would be efficient with better information. More generally, in an environment where the observed behavior of the economy does not conform well with the policymaker's beliefs about the underlying state of the economy, the policymaker ought to properly take into account that much of the information he is provided with describes the economy with substantial error. This, then will call for a cautious response to apparent imbalances in the economy.

It is worth noting that the motivation for this caution differs from the one associated with uncertainty regarding the model's parameters. Following Brainard (1967), it has been recognized that parameter uncertainty may lead a Bayesian policymaker to reduce the policy instrument responsiveness to economic imbalances. The recent contributions by Sack (1997), and Estrella and Mishkin (1998) reinforced this implication for gradualism in the setting of interest rates. However, as Sargent (1998) points out, parameter uncertainty does not necessarily induce gradualist behavior if the policymaker takes a Knightian view of model uncertainty and adopts robust policy control. It remains to be determined whether the stodginess I attribute here to the presence of noise is preserved under robust control. 


\subsection{Rigid Monetary Policy Rules and Inflation Targeting}

Policy reaction functions estimated over long samples invariably produce shifting parameter estimates exhibiting instability. This is sometimes interpreted as reflecting shifts in policy preferences or strategies, suggesting that policy may be formulated in unsystematic fashion. The results shown in figure 5 suggest that this need not be the case. Even if policy were based on a simple reactive rule, mere variations in a policymaker's confidence in his knowledge of the economy in real time would lead to substantial changes in the efficient response of policy to developments in both inflation and the output gap. This is the case even with a stable model of the economy, stable and fixed distributions of supply and demand shocks, and constant preferences. Until a better understanding of the determinants and evolution of confidence regarding our understanding of the economic outlook evolves, it will remain difficult to uncover the underpinnings of the apparent variation in estimated policy reaction functions. Integration of the process of learning from past experience by policymakers (as recently investigated by Sargent, 1998b, and Wieland, 1996) may be essential for a better understanding and evaluation of monetary policy.

This issue also bears on the debate regarding inflation targeting and central bank independence. Some flexibility in the conduct of monetary policy would appear sensible even if the policy goal, such as an explicit inflation target, is outside the control of the central bank. As pointed out by Fischer (1994), "instrument independence" may be desirable even in the absence of "goal independence." Similarly, as reinforced by Bernanke and Mishkin (1997) and Svensson (1998), it is important to distinguish inflation targeting as a framework reflecting a policy objective from the adoption of a rigid rule aiming at stabilizing inflation.

At a practical level, data limitations and their consequences should be taken into consideration in formulating guidelines and performance standards for an inflation targeting

central bank. The extent and influence of data noise should be an important factor in assessing the feasibility of containing inflation within a narrow range. And policy outcomes should be evaluated against realistic performance standards. 


\subsection{Noise and Expectations}

The model I employ does not explicitly examine economic agents' expectations. Several other models employed for policy evaluation incorporate such expectations explicitly. Examples include both structural rational expectations models such as Taylor (1979), Fuhrer (1994), and Orphanides and Wieland (1998), as well as models based more explicitly on optimizing behavior such as Rotemberg and Woodford (1998), and McCallum and Nelson (1998). Clearly, the policymaker's difficulty in interpreting the incoming data remains. But additional problems arise which, if anything, may magnify the consequences of noise.

As is well documented, data noise leads to substantial deterioration in the reliability of forecasts (e.g. Cole, 1969b). Since forecasts influence current outcomes, their reliability is an implicit but important factor in determining the performance of the economy in rational expectations models. But by introducing additional noise in the economy, activist policies may increase the unreliability of these forecasts. Therefore, the evaluation of alternative policies in such models would need to factor the indirect influence of noise on forecasts in addition to the direct effect of noise on policy.

A thornier issue is that with noisy information the policymaker's perception of reality may differ from that of other agents in the economy. For instance, individuals may have better information regarding their own income than the policymaker does. As a result, even if all agents in the economy share common beliefs regarding the true nature of the economy (an unlikely premise), heterogeneity in either the available information or merely the confidence with which that information is being read will result in a divergence between the policymaker's and other agents' expectations about the future. In the presence of noise, explicit modeling of the resulting parallel realities perceived by the policymaker and other agents may become necessary to describe the economic equilibrium. ${ }^{7}$

\footnotetext{
${ }^{7}$ In practice, policymakers may attempt to draw some inference as to the state of private expectations. For inflation sources include household survey data, professional forecasts, information in the prices of nominal and indexed bonds and so forth. Consumer sentiment surveys and surveys of manufacturing managers sometimes provide independent information on consumption and production plans. But as with other data sources, the noise content of this information could be considerable.
} 


\section{Conclusion}

Unless the practical limitations facing monetary policy are properly acknowledged, policy evaluations will always suggest that activist monetary policy can improve macroeconomic performance. Such gains may be illusory. As I show within the context of interest-rate-based monetary policy rules, while short-run economic stabilization gains from pursuing activist policies may appear substantial, these gains all but disappear once the informational limitations facing policymakers are taken into consideration. Indeed, a cautious response to apparent imbalances in the data is appropriate. A prudent policymaker should recognize that much of the information at his disposal is fraught with noise, and avoid overreaction. This caution is especially relevant when considering apparent deviations of aggregate demand from the economy's potential. Though well intentioned, naive policy that ignores such noise may become a source of instability.

Even considering the policymaker's informational limitations, I find that some scope for short-run stabilization remains. However, my experiments only examine the implications of noise. A next step would be to consider simultaneously these informational limitations and uncertainty regarding model specification. Another would be to reexamine alternative strategies for monetary policy. For instance, monetarists have always emphasized the value of monetary aggregates as policy indicators. Difficulties associated with the measurement of money and frequent episodes of unstable velocity have diminished the role of money in monetary policy. ${ }^{8}$ However, as Meltzer (1998) recently reiterated, monetary aggregates continue to provide useful information over longer horizons. Once we recognize that informational problems limit the scope for short-run stabilization, it may be fruitful to reexamine the role of money as a policy indicator.

The main objective of this analysis is to serve as a reminder and provide some concrete evidence for some old wisdoms regarding monetary policy. As Modigliani (1977) pointed

\footnotetext{
${ }^{8}$ For instance, given the uncertainty in estimates of domestic currency holdings (Porter and Judson, 1996), the usefulness of the monetary base for short-run guidance may be extremely limited.
} 
out, the recognition that inappropriately activist monetary policy can be destabilizing "has had a salutary effect on reassessing what stabilization policies can and should do, and on trimming down fine-tuning ambitions" (p. 17). For as Friedman (1967) observed: "The first and most important lesson that history teaches about what monetary policy can do-and it is a lesson of the most profound importance - is that monetary policy can prevent money itself from being a major source of economic disturbance." (p. 106) 


\section{References}

Ball, Laurence (1997), "Efficient Rules for Monetary Policy," NBER Working Paper No. 5952, March.

Bernanke, Ben S., and Frederic S. Mishkin (1997), "Inflation Targeting: A New Framework for Monetary Policy?" Journal of Economic Perspectives, 11(2), 97-116.

Bertsekas, Dimitri (1995), Dynamic Programming and Optimal Control, Vol I, Belmont, MA: Athena Scientific.

Blinder, Alan (1998), Central Banking in Theory and Practice, Cambridge, MA: MIT Press.

Boskin, Michael J., Ellen R. Dulberger, Robert J. Gordon, Zvi Griliches, and Dale W. Jorgenson (1996), "Toward a More Accurate Measure of the Cost of Living," Final Report to the Senate Finance Committee, December 4.

Brainard, William C. (1967), "Uncertainty and the Effectiveness of Policy," American Economic Review, 57, 2, 411-25.

Bryan, Michael F., Stephen G. Cecchetti, and Rodney L. Wiggins II (1997), "Efficient Inflation Estimation," Federal Reserve Bank of Cleveland, Working Paper 9707.

Bryant, Ralph C., Peter Hooper and Catherine Mann eds., (1993), Evaluating Policy Regimes: New Research in Empirical Macroeconomics, Washington DC: Brookings.

Cecchetti, Stephen (1996) "Measuring Short-Run Inflation for Central Bankers," NBER Working Paper, No. 5786, October.

Clarida, Richard, Jordi Gali, and Mark Gertler (1998), "The Science of Monetary Policy," Manuscript, September.

Cole, Rosanne (1969a), Errors in Provisional Estimates of Gross National Product, New York: National Bureau of Economic Research.

Cole, Rosanne (1969b), "Data Errors and Forecasting Accuracy," in Economic Forecasts and Expectations, Jacob Mincer ed., New York: National Bureau of Economic Research.

Fischer, Stanley (1994), "Modern Central Banking," in The Future of Central Banking, Capie F. et al eds., Cambridge, UK: Cambridge University Pres.

Fuhrer, Jeffrey C. (1994), "Optimal Monetary Policy and the Sacrifice Ratio," in Goals, Guidelines, and Constraints Facing Monetary Policymakers, J. Fuhrer, ed., Boston: Federal Reserve Bank of Boston.

Friedman, Milton (1947), "Lerner on the Economics of Control," in Friedman (1953).

Friedman, Milton (1953), Essays in Positive Economics, Chicago: University of Chicago. 
Friedman, Milton (1958), "The Supply of Money and Changes in Prices and Output," in Friedman (1969).

Friedman, Milton (1967), "The Role of Monetary Policy," in Friedman (1969).

Friedman, Milton (1969), The Optimum Quantity of Money and Other Essays, Chicago: University of Chicago.

Greenspan, Alan (1997), "Remarks at the 15th Anniversary Conference of the Center for Economic Policy Research at Stanford University," September 5.

Henderson, Dale and Warwick J. McKibbin (1993), "A Comparison of Some Basic Monetary Policy Regimes for Open Economies: Implications of Different Degrees of Instrument Adjustment and Wage Persistence", Carnegie-Rochester Conference Series on Public Policy (39) 221-318.

King, Mervyn (1997), "Changes in UK Monetary Policy: Rules and Discretion in Practice," Journal of Monetary Economics, 39(1), 81-97, June.

Kohn, Don (1998), "Comments on 'Forward-looking Rules for Monetary Policy'," in Taylor (1998b).

Kuttner, Kenneth (1992), "Monetary Policy with Uncertain Estimates of Potential Output," Economic Perspectives: Federal Reserve Bank of Chicago, January/February, 1992, 2-15.

Levin, Andrew (1996), "A Comparison of Alternative Monetary Policy Rules in the Federal Reserve Board's Multi-Country Model," BIS Conference papers Vol. 2, pp. 340-366.

Levin Andrew, Volker Wieland and John Williams (1998), "Robustness of Simple Policy Rules Under Model Uncertainty," NBER Working Paper, No. 6570, May.

Mankiw, Gregory N., and Matthew D. Shapiro (1986), "News or Noise: An Analysis of GNP Revisions," Survey of Current Business, May, 20-25.

Mauskopf, Eileen (1995), "The Monetary Transmission Mechanism in the United States: Simulations Using the Federal Reserve Board's MPS Model," Financial Structure and the Monetary Policy Transmission Mechanism, Basle, Switzerland: Bank for International Settlements.

McCallum, Bennett T. (1997), "Issues in the Design of Monetary Policy Rules," working paper.

McCallum, Bennett T. (1994), "Specification of Policy Rules and Performance Measures in Multicountry Simulation Studies," Journal of International Money and Finance, 13(3), 259-275, June.

McCallum, Bennett T. and Edward Nelson (1998), "Performance of Operational Policy Rules in An Estimated Semi-Classical Structural Model," NBER Working Paper, No. 6599, June. 
Meltzer, Allan H. (1987), "Limits of Short-Run Stabilization Policy," Economic Inquiry, $25,1-14$.

Meltzer, Allan H. (1998), "Monetarism: The Issues and the Outcome," Atlantic Economic Journal, 26(1), 1-14, March.

Modigliani, Franco (1977), "The Monetarist Controversy or, Should We Forsake Stabilization Policies?" American Economic Review, 67(2), 1-19, March.

Orphanides, Athanasios (1997), "Monetary Policy Rules Based on Real-Time Data," Finance and Economics Discussion Series, 1998-03, Federal Reserve Board, December.

Orphanides, Athanasios, David Small, David Wilcox, and Volker Wieland (1997), "A Quantitative Exploration of the Opportunistic Approach to Disinflation." Finance and Economics Discussion Series, 97-36, Board of Governors of the Federal Reserve System, June.

Orphanides, Athanasios, and Volker Wieland (1998), "Price Stability and Monetary Policy Effectiveness when Nominal Interest Rates are Bounded at Zero," Finance and Economics Discussion Series, 98-35, Board of Governors of the Federal Reserve System, June.

Orphanides, Athanasios, and David Wilcox (1996), "The Opportunistic Approach to Disinflation," Finance and Economics Discussion Series, 96-24, Board of Governors of the Federal Reserve System, May.

Orphanides, Athanasios, and Simon van Norden (in process), "The Reliability of Output Gap Estimates in Real Time." working paper.

Porter, Richard, and Ruth Judson (1996), "The Location of U.S. Currency: How Much Is Abroad?" Federal Reserve Bulletin, 82(10), October, 883-903.

Rotemberg, Julio and Michael Woodford (1998), "Interest-Rate Rules in an Estimated Sticky Price Model.” NBER Working Paper, No. 6618, June.

Rudebusch, Glenn and Lars Svensson (1998), "Policy Rules for Inflation Targeting." NBER Working Paper, No. 6512, April.

Sack, Brian (1988), "Does the Fed Act Gradually? A VAR Analysis," Finance and Economics Discussion Series, 98-17, Board of Governors of the Federal Reserve System, March.

Sargent, Thomas (1998a), "Discussion of 'Policy Rules for Open Economies'," in Taylor (1998b).

Sargent, Thomas (1998b), The Conquest of American Inflation, forthcoming. 
Shapiro, Matthew D. and David W. Wilcox (1996), "Mismeasurement in the Consumer Price Index: An Evaluation," NBER Macroeconomic Annual.

Svensson, Lars E. O. (1997), "Inflation Forecast Targeting: Implementing and Monitoring Inflation Targets," European Economic Review, 41(6), June, 1111-1146.

Svensson, Lars E. O. (1998), "Inflation Targeting as a Monetary Policy Rule," working paper, August.

Taylor, John B. (1979), "Estimation and Control of a Macroeconomic Model with Rational Expectations," Econometrica, 47(5), 1267-86.

Taylor, John B. (1993), "Discretion versus Policy Rules in Practice," Carnegie-Rochester Conference Series on Public Policy, 39, December, 195-214.

Taylor, John B. (1998a), "The Robustness and Efficiency of Monetary Policy Rules as Guidelines for Interest Rate Setting by the European Central Bank," May.

Taylor, John B., ed., (1998b), Monetary Policy Rules, Chicago: University of Chicago (forthcoming).

Wieland, Volker (1996), "Monetary Policy, Parameter Uncertainty and Optimal Learning," Federal Reserve, August.

Wieland, Volker (1998), "Monetary Policy under Uncertainty about the Natural Unemployment Rate," Finance and Economics Discussion Series, 98-22, Board of Governors of the Federal Reserve System.

Zellner, Arnold (1958), "A Statistical Analysis of Provisional Estimates of Gross National Product and its Components, and of Personal Saving," Journal of the American Statistical Association, 53, 281, 54-65, March. 


\section{Appendix}

\section{Control with Perfect Information}

To obtain the solution, it is convenient to first write the problem in state space form. Let:

$$
\mathbf{X}_{t}=\left[\begin{array}{c}
\pi_{t}-\pi^{*} \\
y_{t}
\end{array}\right], \mathbf{V}_{t}=\left[\begin{array}{c}
e_{t}+\alpha u_{t} \\
u_{t}
\end{array}\right], \mathbf{A}=\left[\begin{array}{cc}
1 & \alpha \rho \\
0 & \rho
\end{array}\right], \quad \text { and } \mathbf{B}=\left[\begin{array}{c}
-\alpha \xi \\
-\xi
\end{array}\right]
$$

Then, the economy can be compactly written as:

$$
\mathbf{X}_{t+1}=\mathbf{A} \mathbf{X}_{t}+\mathbf{B}\left(r-r^{*}\right)+V_{t+1}
$$

The policy-maker objective can be written in terms of the quadratic form $\mathbf{X}^{\prime} \mathbf{Q X}$ where $\mathbf{Q}$ reflects the weights in the policymaker's preferences:

$$
\mathbf{Q}=\left[\begin{array}{cc}
\omega & 0 \\
0 & 1-\omega
\end{array}\right]
$$

Following standard results from linear-quadratic control theory, for instance as described in Bertsekas (1995), the optimal policy is given by:

$$
r_{t}-r^{*}=-\left(\mathbf{B}^{\prime} \mathbf{K B}\right)^{-1} \mathbf{B}^{\prime} \mathbf{K} \mathbf{A} \mathbf{X}_{t}
$$

where $\mathbf{K}$ solves the algebraic Riccati equation:

$$
\mathbf{K}=\mathbf{A}^{\prime}\left(\mathbf{K}-\mathbf{K B}\left(\mathbf{B}^{\prime} \mathbf{K B}\right)^{-1} \mathbf{B}^{\prime} \mathbf{K}\right) \mathbf{A}+\mathbf{Q}
$$

This yields the solution shown in the text for $\gamma^{N}$ and $\delta^{N}$. 
Table 1

Summary Statistics: 1980H1-1992H2

\begin{tabular}{rrcrrr}
\hline \hline & Mean & SD & \multicolumn{1}{c}{ Min } & \multicolumn{1}{c}{ Max } & \multicolumn{1}{c}{ AR } \\
\hline$y_{t}$ & -1.64 & 2.44 & -7.36 & 1.99 & 0.87 \\
$\tilde{y}_{t}$ & -3.99 & 3.46 & -10.67 & 1.93 & 0.90 \\
$z_{t}$ & 2.35 & 1.53 & -0.07 & 5.62 & 0.81 \\
$\pi_{t}$ & 4.60 & 2.27 & 1.89 & 10.02 & 0.75 \\
$\tilde{\pi}_{t}$ & 4.48 & 2.37 & 2.02 & 10.44 & 0.67 \\
$x_{t}$ & 0.12 & 0.69 & -1.90 & 1.53 & -0.07 \\
\hline \hline
\end{tabular}

Notes: $y_{t}$ is the output gap, defined as actual real output minus potential, as a fraction of potential, in percent, based on data available at the end of 1994. $\tilde{y}_{t}$ is the corresponding realtime measure. $\pi_{t}$ is inflation of the implicit deflator from the last quarter of the previous period to the last quarter of the current period, in percent annual rate, based on data available at the end of 1994. $\tilde{\pi}_{t}$ is the corresponding real-time measure. $x_{t}$ is the difference between the final and real-time inflation series. $z_{t}$ is the difference between the final and realtime output gaps. SD is the standard deviation and AR is the first order serial correlation coefficient. 
Table 2

\section{Efficient Response Parameters}

\begin{tabular}{ccccccc}
\hline \hline & \multicolumn{2}{c}{$\omega=0.25$} & \multicolumn{2}{c}{$\omega=0.50$} & \multicolumn{2}{c}{$\omega=0.75$} \\
Noise & $\gamma$ & $\delta$ & $\gamma$ & $\delta$ & $\gamma$ & $\delta$ \\
\hline$s=0$ & 1.87 & 2.61 & 3.12 & 2.61 & 5.05 & 2.61 \\
$s=1$ & 1.18 & 0.77 & 2.21 & 1.05 & 3.87 & 1.34 \\
$s=2$ & 0.66 & 0.14 & 1.15 & 0.20 & 2.02 & 0.32 \\
\hline \hline
\end{tabular}

Notes: The entries reflect efficient choices of the response parameters $\gamma$ and $\delta$ when policy follows the rule: $\tilde{r}_{t}-r^{*}=\gamma\left(\tilde{\pi}_{t}-\pi^{*}\right)+\delta \tilde{y}_{t}$, corresponding to alternative preference weights, $\omega$, and levels of noise, $s$. 
Figure 1

\section{Inflation Based on Real-Time and Final Data Semiannual Data}

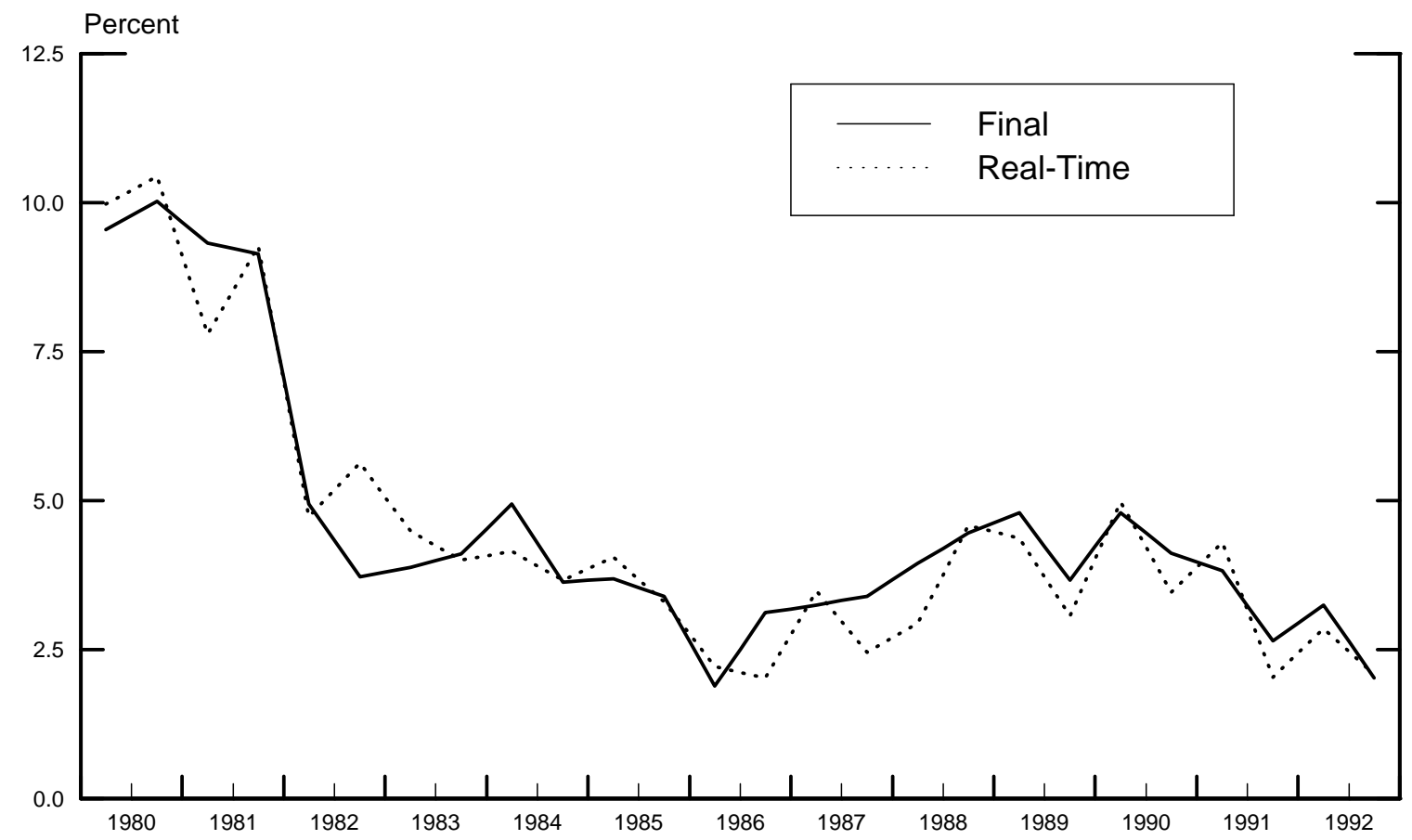

Notes: Inflation is constructed as the rate of change in the implicit output deflator during the period at an annual rate using seasonally adjusted data. Real-time data reflect information as of May and November for the first and second halves of each year respectively. Final data reflect historical information with data available at the end of 1994 . 
Figure 2

\section{Output Gap Based on Real-Time and Final Data Semiannual Data}

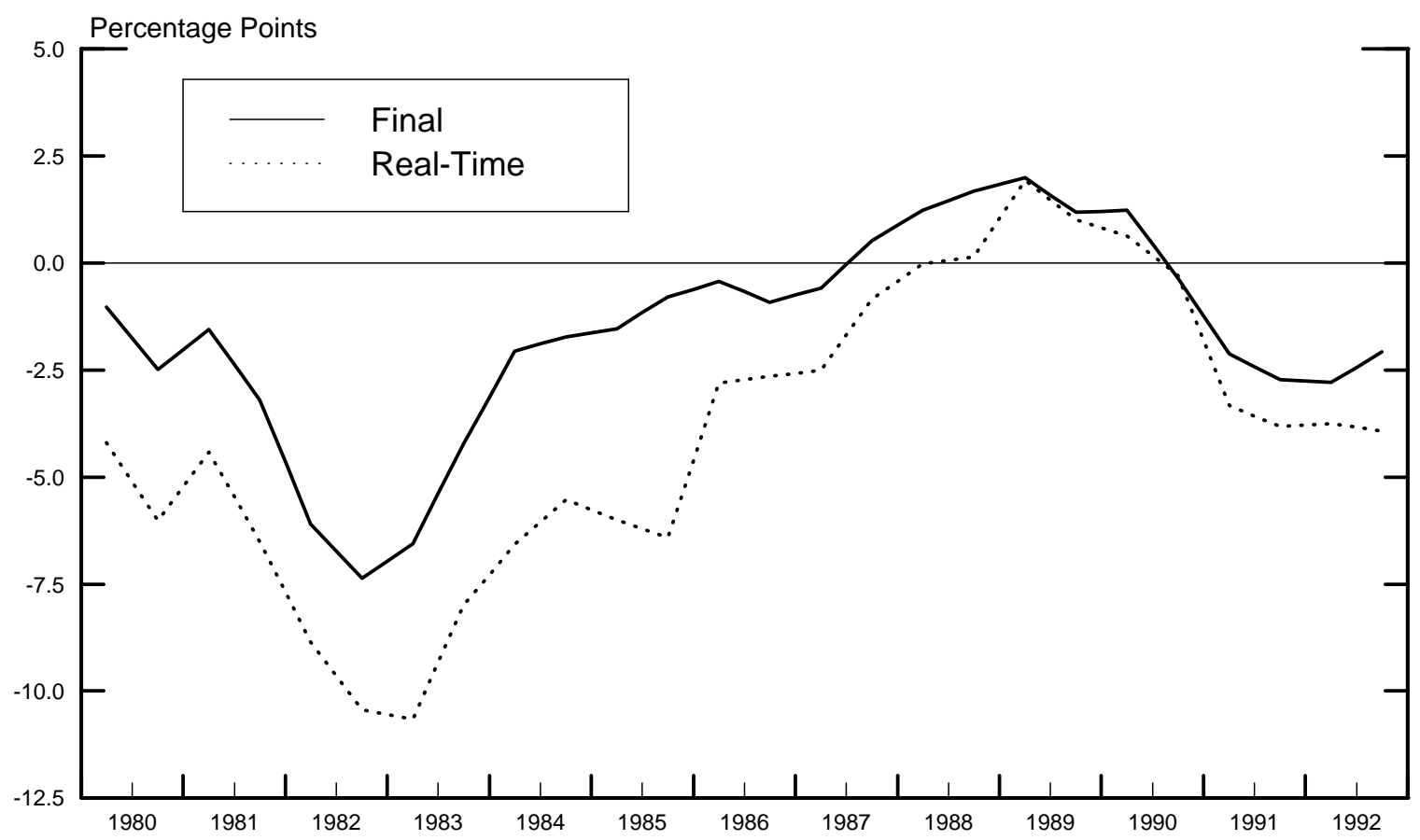

Notes: The output gap is the average difference between real output and potential output, measured as a fraction of potential output using seasonally adjusted data. Real-time data reflect information as of May and November for the first and second halves of each year respectively. Final data reflect historical information with data available at the end of 1994 . 
Figure 3

\section{Output-Inflation Variability Frontier with Naive Control}

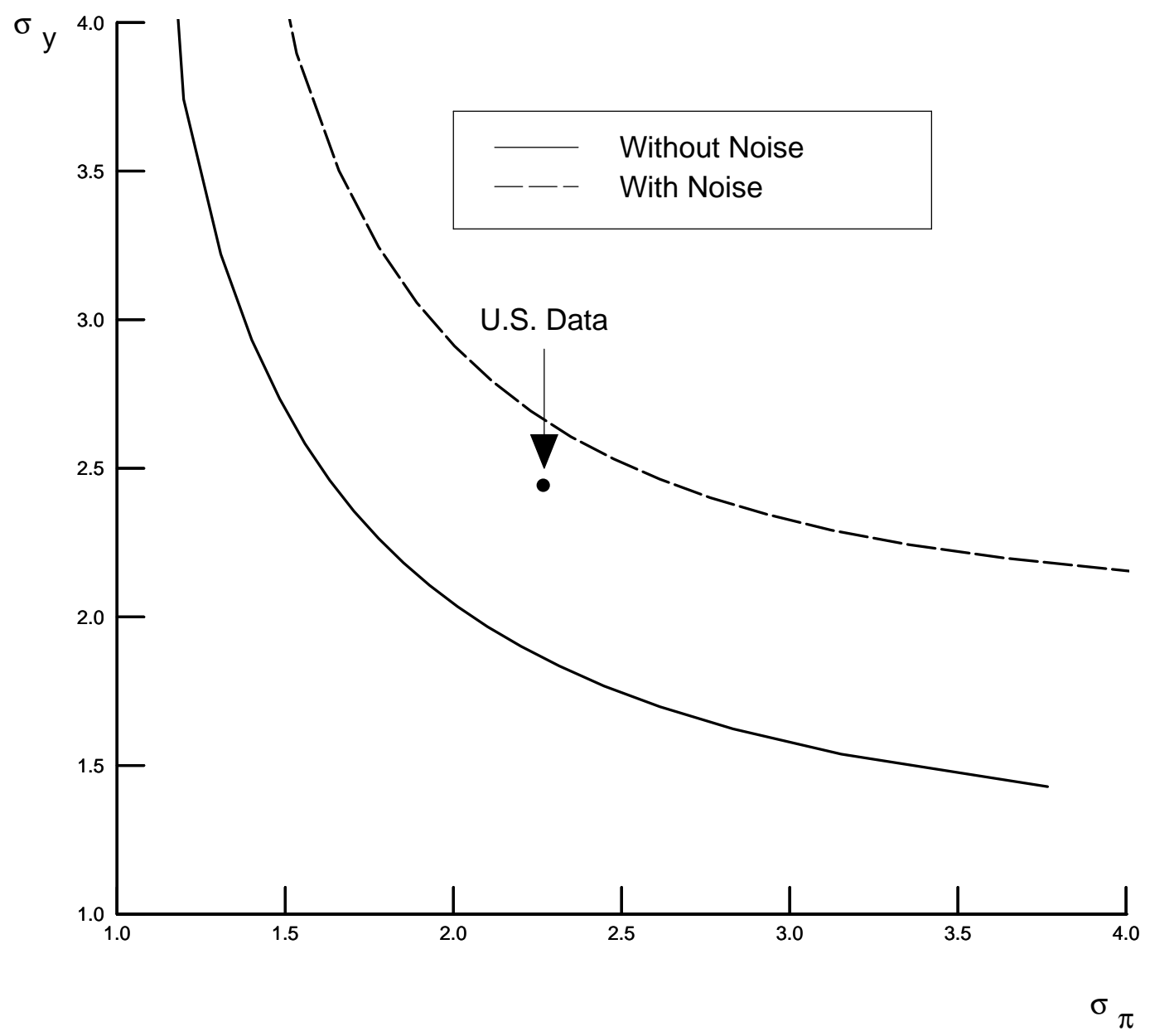

Notes: The solid line shows the (infeasible) frontier constructed assuming no noise in the data. The dashed line shows the variability that would actually result if the naive control policies were followed. 
Figure 4

\section{Output-Inflation Variability Frontiers with Noise}

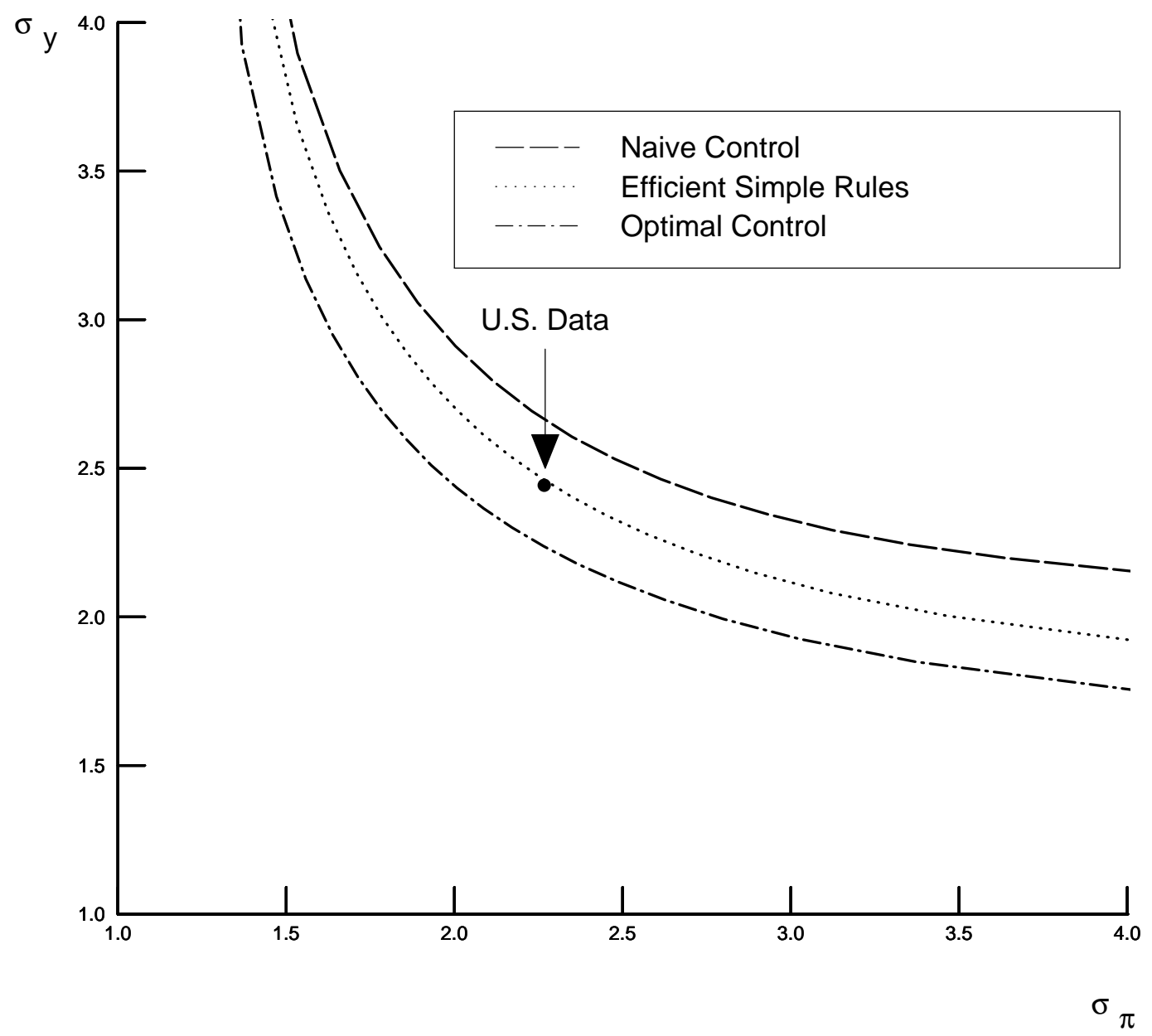

Notes: The efficient simple rule frontier reflects outcomes when policy follows the rule: $\tilde{r}_{t}-r^{*}=\gamma\left(\tilde{\pi}_{t}-\pi^{*}\right)+\delta \tilde{y}_{t}$, with efficient choice of the response parameters $\gamma, \delta$. 
Figure 5

\section{Efficient Simple Rule Response to Inflation and Output}

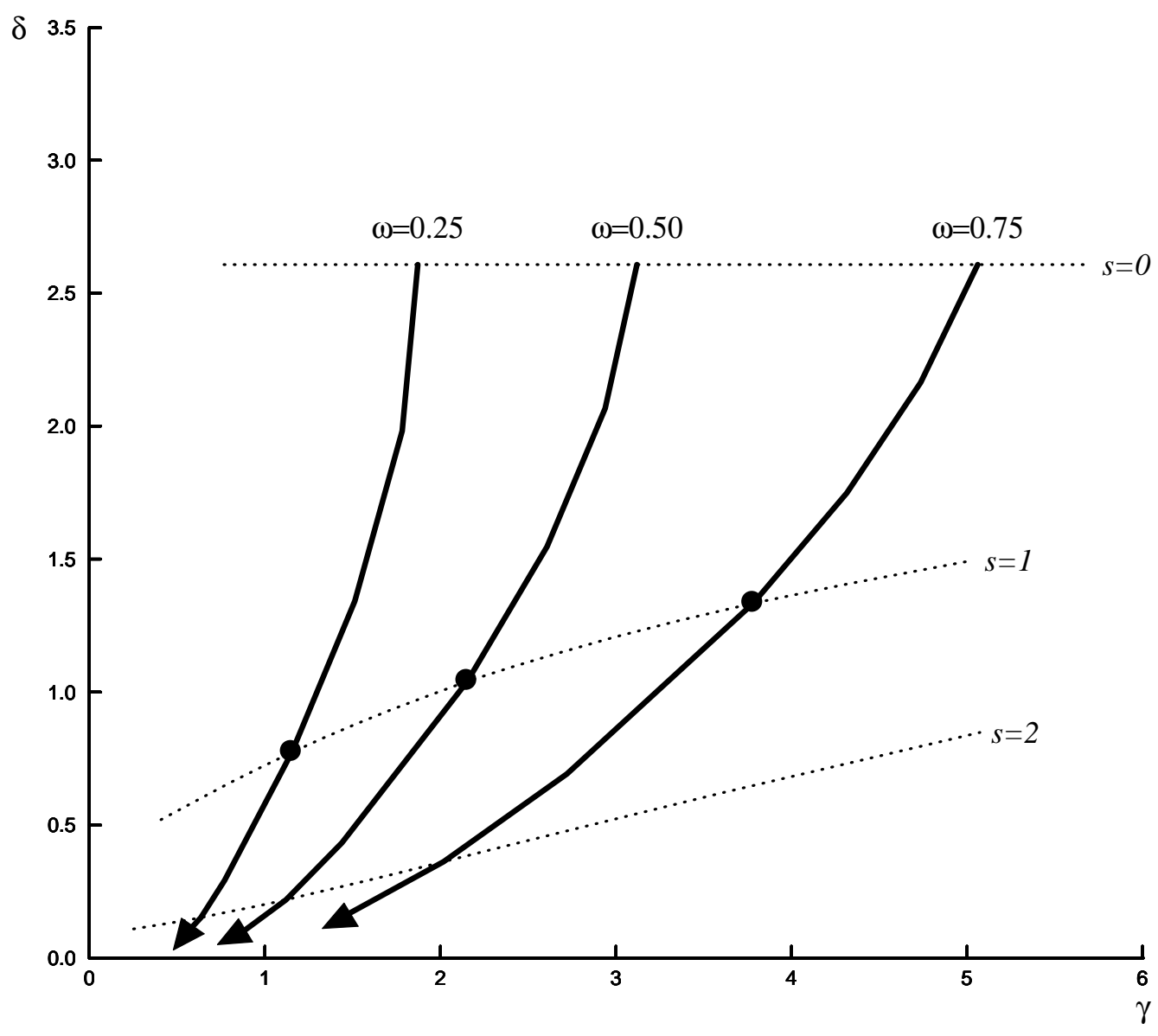

Notes: Points on the figure reflect efficient choices of the response parameters $\gamma$ and $\delta$ when policy follows the rule: $\tilde{r}_{t}-r^{*}=\gamma\left(\tilde{\pi}_{t}-\pi^{*}\right)+\delta \tilde{y}_{t}$. The solid lines show variation in efficient choices corresponding to alternative preference weights, $\omega$, for different levels of noise, $s$. The arrows, indicate the direction of movement of the efficient choices with increasing levels of noise. The dotted lines reflect iso-noise loci of efficient choices with $s=0$ indicating efficient choices in the absence of noise, $s=1$ reflecting the estimated level of noise in the data, and $s=2$ reflecting noise with standard deviation twice the estimated level. 